\title{
Targeting the Zoonotic Potential of Bovine Mastitis by an Integrated One-Health Approach
}

\author{
Sudipa Maity ${ }^{1}$ and Kiran Ambatipudi ${ }^{2}$ \\ ${ }^{1}$ Indian Institute of Technology Roorkee \\ ${ }^{2}$ Affiliation not available
}

May 14, 2020

\begin{abstract}
In the midst of modernization of human lifestyle with the profound effect of sophisticated technologies, pathogens in parallel have also evolved gradually to stay masked and smuggled their ways into our lives. Of different pathogens, zoonotic microbes are the most challenging to control, attributed to faulty surveillance systems to monitor the emergence of any pathogens at the humananimal interface. Amongst different infectious diseases in bovines, mastitis is a prototypic emerging and reemerging disease caused by pathogenic microbes that have overcome a series of hierarchical barriers resulting in zoonotic transmission. Although it has been annoyingly persistent since ancient times, it has never been a focus for desperate measures. However, the most critical is the chronic asymptomatic subclinical mastitis that results in cut-by-cut torture to not only the animals but also to the global economy. Despite the rapid technological advancement, identification of mastitis in subclinical form at the local community level is still improbable, leading to a high chance of the pathogenic and antimicrobial spillover. Understanding the complex sociological and ecological factors influencing disease transmission risks and pathogen containment remains unelucidated. Multiple factors are essential for the successful detection and containment of pathogens that have prompted the initiation of the "One Health" approach. Nevertheless, there is a lack of collaborative approach between the local and global strategists to suggest and implement checkpoints at different horizons to control mastitis. Here, we review the evolution of these pathogens in the reservoir host, their zoonotic potential and the pros and cons of current management strategies. We also address the extent of success in implementing a concerted approach like "One Health One Welfare," which calls for interdisciplinary collaboration between professionals in human, animal and environmental health along with multi-omics to keep the pathogens at bay.
\end{abstract}

\section{Introduction}

Bovine mastitis is the costliest infection of the mammary gland and is a menace to both animal health and productivity, resulting in a considerable loss in milk yield and quality thereby causing economic perils for both the farmers and dairy industry globally (Verma \& Ambatipudi, 2016). The mastitic pathogens co-evolve with the host to stay masked and smuggle their way into our lives by overcoming series of hierarchical barriers. Although aligning these barriers in time and space is theoretically unusual for provoking a zoonotic transmission, it is becoming easier day by day as the line dividing humans and animals are getting thinner into a thread. Subsequently these pathogens find routes to be transmitted to other animals and/or humans through infected quarters, milking equipment, or contaminated food products. Although it has been annoyingly persistent since ancient times, it has never been a focus for desperate measures possibly because it does not stand out as a noisy killer. However, it shows a substantial rate of mortality and morbidity with metastatic bacterial spread and complicated infection (Mazzariol et al., 2018). Like the rest of the zoonosis, in mastitis, the concerning stage is the asymptomatic chronic subclinical (SCM) stage which is zoonotically more devastating than the clinical $(\mathrm{CM})$ stage and precedes for an extended period with no visual symptoms. For example, it is generally believed that if a cow in a herd has been diagnosed with CM, it is most likely that several other cows could be at the SCM stage and likely progressing towards CM if not diagnosed early 
and therapeutically intervened.

Currently, there is an increased pressure on various governments around the world to control the transmission of a contagious disease such as mastitis due to a surge in international trade, globalization and global warming (Zadoks \& Fitzpatrick, 2009). Consequently, the Food and Agriculture Organization (FAO), Agricultural Outlook, 2019 stated that hidden disease like SCM needs to be detected at the initial stage by producers since effective management relies on a better understanding of disease identification and treatment and public awareness (Tolosa, Verbeke, Piepers, Supré, \& De Vliegher, 2013). For large milk producing countries like India (Landes, Cessna, Kuberka, \& Jones, 2017), it is imperative to have regulations to improve milk quality through incentives or strict penalties, for example, with low or high somatic cell count (SCC). In addition to the lack of adequate quality control measures and appropriate and easy-to-use device to check SCC at the pen side (Oliver, Jayarao, \& Almeida, 2005), there are high chances of milk getting contaminated while being procured from the farm to the processing plants. While most milk in developed countries is tested for high SCC and pasteurized before it reaches consumers, in developing countries, milk is often consumed unpasteurized (Lucey, 2015), or with high SCC as it is sold by local dairies contributing significantly to the transmission of zoonotic pathogens in the food chain through the milk and dairy food products.

All the zoonotic outbreaks, be it sporadic, dead-end infections without adaptation to humans (e.g., Ebola virus) or stably adaptation to humans, leading to sustained person-to-person transmission (SARS), have given a critical insight into the development of genetic diversity by the pathogens and raised serious questions that can no longer be responded to by only veterinarians. Until recently, bovine mastitis was a concern just for dairy industries. However, looking at the present scenario of zoonotic transmission and antimicrobial resistance, it is justified to introduce it as a global problem. Despite tremendous advances made in different omics- and diagnostic technologies, these pandemic outbreaks demonstrated that technology alone has not been successful in predicting or diagnosing such a complex disease that has chances of its spillover in so many social scales. This calls for a concerted concept like the One-Health approach that will engage national and international partners to control the transmission. Our objective is to provide a framework that focuses on the necessity and the extent of applicability of the One-Health approach to control the zoonotic transmission of bovine mastitis. To this end, we have reviewed the battle between host and pathogen and discussed the mechanisms that the pathogens employ to successfully evade the immune system. Furthermore, to understand the zoonotic importance of mastitis, we have highlighted different evidences and management to control the spillover from animals to humans and vice-versa and how it impacts the global food chain. This review will provide a milestone to address a long-neglected zoonotic disease and an alternative way of understanding the epidemiology keeping the triad of animal, human and environmental welfare in mind.

\section{Host-Pathogen Combat and Immune Evasion}

Bovine mastitis can be considered as a classic example of the "zoonotic spillover" where a zoonotic pathogen promotes a "spillover transmission" by overcoming a series of hierarchical barriers for the establishment and spread of infection from reservoir host to environment (Rodriguez-Morales et al., 2020). Epidemiologically, pathogens causing bovine mastitis can be broadly categorized into contagious and environmental pathogens. The two major contagious pathogens responsible for emergence and re-emergence of mastitic zoonosis are $S$. aureusand Streptococcus agalactiae, with few studies reportingStreptococcus uberis, Mycoplasma spp . and Corynebacterium bovis as the main culprits for epidemic outbreaks. In contrast, environmental pathogens such as Escherichia coli, Klebsiella spp.and Streptococcus dysgalactiae have no recorded history of outbreaks except for acute clinical symptoms in infected animals (Dufour, Labrie, \& Jacques, 2019). These diverse mastitis-causing pathogens induce different immune responses in the mammary gland, and therefore, the host requires highly specific pathogen-dependent responses for protection. For instance, the non-immune anatomical barrier and a plethora of immune-mediated defense mechanisms, including innate and adaptive immune responses play a critical role in reducing the incidence and establishment of infection in the bovine mammary gland (Rainard, Cunha, \& Gilbert, 2016). Normally, the teat canal, lined with waxy keratin, is tightly closed by sphincter preventing pathogen entry either by obstructing their migration and/or assisting in combating the organism (Capuco, Wood, Bright, Miller, \& Bitman, 1990). However, during parturition, 
the first line of defense is compromised when the keratin lining is flushed out, and the teat canal is distended for a minimum of $2 \mathrm{~h}$ (Capuco et al., 1992), making the mammary gland vulnerable to infection. Besides, the udder health is under a constant threat posed by primarily inappropriate managerial (e.g. housing, milking machines, bedding and hygiene), environmental (e.g. climate, pathogens) and cow factors (e.g. genetic, SCC, parity) that add to the favors for the invasion and spread of the bacteria (Ouweltjes, Beerda, Windig, Calus, \& Veerkamp, 2007). Consequently, any change in the status quoallows the pathogens to pass through the teat canal to find a warm, moist, and nutrient-rich environment within the gland favorable for their rapid growth and multiplication.

The interaction between mastitis-causing pathogens and the host immune system is intricate due to their ability to co-evolve, recognize, respond and adapt to each other. Nevertheless, microbial pathogens have developed various strategies to alter, evade and escape host defenses for their survival. Similarly, the host immune system is also adaptive and has a large arsenal to control and/or eliminate the microbial threat. The mammary microenvironment comprising luminal and basal epithelial cells, fibroblasts, endothelial cells and stromal matrix, and the immune cells engage in a complex and interweaving network of interactions following a pathogen invasion (Booth, Boulanger, Anderson, \& Smith, 2011). Even so, it has been widely accepted that susceptibility of individuals within a given species differs from the same microbial pathogen due to their inherent genetic make-up, innate and adaptive immune responses, particularly the acquired immunological memory and nature of the microbial pathogen (Sela, Euler, Correa da Rosa, \& Fischetti, 2018). Innate immunity is relatively non-specific with rapid kinetics and is tightly integrated with adaptive immunity offering a highly specific response using a diverse repertoire of antigen-specific receptors. Although, the various components of the mammary microenvironment work in collaboration, both locally and systemically, in an attempt to confront the specific mastitis pathogens invading the mammary gland; the outcome of the response is contingent to the persistence of the infection, and the interaction between the pathogen and the host immune make up.

The invading pathogen employs several immune evasion strategies that primarily include hiding from the host immunity, interfering with the function of the immune system and destroying the immune components. For example, pathogens like $S$. aureus and $S$. agalactiae invade by adhering to the host cell surface via a capsular polysaccharide/adhesion and subsequently multiply across different layers of the mammary gland (Toniolo et al., 2015). This process is very critical for the production of two closely related polysaccharidespoly-N-acetylglucosamine and polysaccharide intercellular adhesin necessary for biofilm formation (O'Neill et al., 2007). Subsequently, biofilm enables the pathogens to invade epithelial cells and settle into deeper parts of the mammary gland (Hensen, Pavičić, Lohuis, \& Poutrel, 2000) allowing the microorganisms to survive and multiply within the epithelial cells; hide from the host defense mechanisms and are resistant to virtually all antimicrobial agents. Several possible mechanisms are known to be responsible for the development of resistance of biofilms to antimicrobial agents that include (1) delayed infiltration of the antimicrobial agents through the biofilm matrix (Srinandan, Elango, Gnanadhas, \& Chakravortty, 2015); (2) growth rate of biofilm organisms (W. Liu et al., 2016); (3) physiological changes due to the biofilm mode of growth giving rise to antimicrobial-resistant (AMR) pathogens (Tassinari et al., 2019). Another persistent problem is the overuse of antibiotics during dry period to reduce intramammary infection which also comes with a possible consequence of developing AMR (Berry \& Hillerton, 2002) and creating a myriad of AMR genes that could undergo horizontal gene transfer into other novel opportunistic pathogens. Eventually, the resistant pathogens, produced toxins and the residual antibiotics gain access into the global food chain by finding different routes like manure to plants, contaminated fish in water, meat and milk from infected animals (Fig.1).

All the above factors thereby contribute significantly to the complexities associated with eradication and persistent intramammary infections with frequent recurrent clinical episodes and long-term increases in milk SCC. Of note, S. aureus particularly expresses several factors including modifications of cell surface to compromise the effectiveness of neutrophils and macrophages, inhibit complement activation and neutrophil chemotaxis or lyse neutrophils, and neutralizes antimicrobial defensin peptides. Once the bacterium gains a foothold in the host and starts to grow, several chemoattractants are released that are specifically recognized 
by neutrophils, resulting in a strong chemotactic response (Haas et al., 2004). However, approximately $60 \%$ of $S$. aureus strains secrete the chemotaxis inhibitory protein (CHIPS), which interferes with neutrophil chemotaxis and extravasation, leading to immune evasion (Haas et al., 2004). Another important factor that contributes to the recurrence of the infection and host vulnerability is innate resistance to phagocytic killing, including interference with endosome fusion and release of antimicrobial substances (Gresham et al., 2000). Furthermore, the bacterium avoids the lethal effects of oxygen free radicals that are formed during the respiratory burst (G. Y. Liu et al., 2005). Taken together, the pathogens have evolved different strategies through their virulence mechanisms and immune evasion techniques to first survive and multiply in the host and subsequently promote the "spillover transmission" via different vectors to different hosts within or between herds.

\section{Long Lived Zoonotic Pathogens of Bovine Mastitis}

Milk is an important part of the human diet with a rich source of nutrients to support the growth of pathogens. Mastitic milk poses a serious threat to human health since it could act as a source for shedding bacteria and food toxin infection through milk (Schamberger, Phillips, Jacobs, \& Diez-Gonzalez, 2004). Although CM is pathologically and economically critical, surprisingly is not considered important from a zoonotic perspective since abnormalities in milk are visible and discarded, thereby preventing the pathogen from entering the food chain. In contrast, milk from SCM has a higher possibility of zoonotic transmission, as it cannot be detected due to asymptomatic nature. This can be exemplified in incidents where infected milk without any observable signs gets mixed into bulk milk (Leitner et al., 2019), resulting in contamination and a source of infection to humans when consumed raw, or with incomplete and faulty pasteurization. There are several reports that have stated zoonotic transmission of pathogenic strains causing bovine mastitis by close proximity and by milk and meat into the food chain (listed in Table 1). However, to date, there are still no on-site diagnostic kits and the only successful way to detect SCM, relies on rigorous, although uncertain, individual cow records or cow-side SCC testing, otherwise, the battle is almost impossible to win.

Of the different pathogens responsible for zoonosis,staphylococcal infections have been widespread and complicated to contain due to wide range of pathogenic factors responsible for attaching, colonizing, invading, and infecting the host and the route of transmission includes multiple sources like skin, flies, bar environment and human contacts and equipment. The emergence of a particular group of $S$. aureus strains, for instance, MRSA, has been more influential in zoonosis since the first outbreak in humans in 1961. MRSA are classified into hospital-associated (HA), community-associated (CA) and livestock-associated (LA), with approximately $20-40 \%$ mastitic cases with no visual symptoms in cattle that are caused by LA-MRSA in India (Mahanti et al., 2020). It is primarily responsible for the zoonotic transmission of MRSA from cattle to humans (VAN Cleef et al., 2011). Several reports described different sequence types (STs) of LA-MRSA (e.g. ST398, CC130) (Anjum et al., 2019; C.-J. Chen et al., 2018; Tegegne et al., 2019) that were initially thought to be bovine-specific but have also been found in human clinical isolates highlighting the potential of farm animals acting as a reservoir of infection to other farm animals and humans (Fitzgerald, 2012; García-Álvarez et al., 2011a; Gavin K. Paterson, Harrison, \& Holmes, 2014). Although the first report of MRSA in bovine milk which came out in Belgium, was possibly transmitted by horizontal transfer through hands of milkman (Devriese \& Hommez, 1975), there are subsequent reports from other counties like Hungary (Juhász-Kaszanyitzky et al., 2007), the Netherlands (Van Loo et al., 2007) and Central Europe (Witte, Strommenger, Stanek, \& Cuny, 2007) who revealed transmission of MRSA from cattle to humans either via close proximity $\mathrm{r}$ food consumption of products (Table 1). Nevertheless, these studies did not suggest any particular events of casualties in milking practices or other management system responsible for such transmission. MRSA strains are also found in other livestocks and were responsible for transmission to humans (Boss et al., 2016; Ferreira et al., 2011; Lewis et al., 2008; van Duijkeren et al., 2011) ; but so far no reports stated events of host switch from bovines to other animals.

Into the bargain is $S$. agalactiae another potent zoonotic pathogen responsible for SCM. For example, $S$. agalactiae in the 1950s; was the most common mastitis-causing bacterium among dairy cattle in Europe (Lyhs et al., 2016a). Interestingly, S. agalactiae has a shorter life span in the environment, but it can grow 
and multiply indefinitely as an obligate pathogen within the mammary gland (Rosini \& Margarit, 2015). Additionally, just like $S$. aureus, it also can produce biofilms and provide innate resistance to the majority of the drugs. Several publications on S. agalactiae from humans and cattle have been reported to form distinct populations of the core genome (S. L. Chen, 2019; Kayansamruaj et al., 2019; Lyhs et al., 2016b) and studies have indicated existence of distinct $S$. agalactiaesubtypes with difference in their host specificities and pathogenic potentials. However, in spite of low transmission history unlike MRSA, there are instances that documented human-associated isolates that have the necessary virulence factors to occasionally cause bovine infections, as indicated by recent MLST study (Bisharat et al., 2004). The most prevalent ST being ST1 followed by ST196, which was previously thought to be bovine specific, has also been recognized as an emerging human pathogen. Besides, more recently a study in Northern Europe demonstrated that more than $54 \%$ of isolates with STs - 1, 8, 12, 23, and 196 affects both bovines and humans (Lyhs et al., 2016c). Again, the most dangerous part of the story is that these STs are more commonly associated with asymptomatic carriage rather than causing infection (Lyhs et al., 2016a) which brings us back to the dead-end or failure to diagnose the infection. Although the control of $S$. agalactiae has been a little successful and less torturous unlike $S$. aureus if the dairy industries adhered to the recommended control strategies (Andersen, Pedersen, Aarestrup, \& Chriél, 2003; Piepers et al., 2007).

The recognition of zoonotic pathogens as a vital component of a global health system is essential in the study of bovine mastitis. In most developing countries, the implementation of mastitis control programs has been a slow and inadequate process, leading to the historical misuse of antibiotics in the veterinary field. The delay in establishing the control programs have become increasingly evident in the spread of microbial resistance and rapid transmission of pathogenic strains like MRSA from cattle to humans. To add insults to injury, the spread of zoonosis is supported by limited between and within-herd biosecurity (Layton, Choudhary, \& Bean, 2017). A number of factors such as migration, travel, trade and changing climates put a never-ending threat on the zoonotic outbreak. Above all, global exchange, intensive livestock rearing and international trade make it almost impossible to maintain biosecurity in the boarders (Gushulak \& MacPherson, 2004). With the rising rate of contact between humans and cattle, there are several evidences that even showed human as a potential source of zoonosis to the bovines (Cobo-Angel et al., 2019a). This calls for an establishment of a strong concerted framework like One-Health approach which includes biosecurity that can take a number of different forms and are generally heavily weighted towards prevention of infection rather than treatment.

\section{Management Strategies to Make or Break the Chain of Infection}

The "White Revolution" played an important role in transforming the dairy industry from stagnation to become a world leader in milk production and eradication of malpractices. According to UN FAO, India has over 75 million dairy farms (Farm \& Network, 2011), more than anywhere else in the world, which indeed requires a holistic approach to keep mastitis at bay. As early as the 1960s, numerous researchers at the National Mastitis Council (NMC) established various standards to prevent and control the spread of the disease across dairy farms through a five-point mastitis program, which was subsequently finalized into a ten-point (with sub points) mastitis control plan (NMC, 2016). This program was based on an integrated strategy that included setting of goals, appraisal of the current farm systems, application of appropriate farm-specific interventions and monitoring of outcomes.

Mastitis is a complex multifactorial disease involving multiple players (e.g. bacteria, animals and farmers) and factors (management and environment) that work as cogs in the wheel for cluster and community spread, resulting in ultimate crossing of zoonotic barriers. Thus, it is imperative to have 'grass-root management' strategies at different hierarchy (herd, cow, or quarter) levels to determine the cause and variability in the outcome (e.g. somatic cell count, presence of intramammary infection) for systematic intervention. However, it is well established that factors like poor bedding hygiene (e.g. environmental pathogens), erroneously managed milking equipment (e.g. contagious pathogens), poorly-ventilated and sanitized environment of the grazing area and milking parlor act as driving forces to mastitis. Nevertheless, the focus is often on the most obvious causes, such as the milking technique, or the hygiene of the lactating animals' accommodation, while, in reality, the actual problem could also lie on the physiological states (e.g. dry cow, pregnant heifers). 
Although, the solution spectrum for maintaining a clean-cut udder is mostly similar for all farms but the problem often lies on the variability of the cause of the disease that differ across farms. Considering the diverse dairy structure, geographical and climatic conditions, there may not be a simple one-step solution but farmand country- specific control measures to prevent the spread of the disease. Thus, different management systems and control programs have to be designed and implemented to improve animal health and welfare of the dairy industry. For instance, International Dairy Federation (IDF) formed a questionnaire and sent it to members of the Standing Committee on Animal Health and Welfare (SCAHW) in 2014, intending to map the health status and interest on animal welfare in different countries. Interestingly, the responses gave a bird's view of the diversity in the dairy sector and steps adopted by several countries to control mastitis.

In India, the National Academy of Agricultural Sciences (NAAS), in a session based on "Mastitis Management in Dairy Animals," in 2012, discussed suitable national strategies for effective prevention and control of mastitis. The major objectives focused on epidemiological investigations, including identification of risk factors at the farm level, major pathogen(s) involved and host susceptibility. Furthermore, policy measures set by NAAS encompassed formulation of coordinated research for the disease control and promote the concept of "Clean Milk"; providing incentives to the farmers in the form of a better price for clean milk and establishing various control centers for screening SCC and total bacterial count to assess milk quality (NAAS, 2013). Similarly, a detailed mastitis control plan devised and tested in a randomized controlled trial in the UK during 2004-2005 was successful in reducing CM and new infections by approximately $20 \%$ (Green, Bradley, Medley, \& Browne, 2007). Subsequently, the policy was rolled out as a national scheme in 2009 as the Agriculture and Horticulture Development Board (AHDB) Dairy Mastitis Control Plan (DMCP) (Green et al., 2007), delivered by trained veterinarians and consultants through data analysis, detailed questionnaire and on-farm observations and measurements. Consequently, farm-specific recommendations were prioritized for discussion with the farmer to implement changes most relevant to the underlying epidemiology of mastitis. Since the launch of DMCP in 2009, over 300 plan deliverers have been trained and more than 2000 farms have been involved in the plan, representing approximately $20 \%$ of the national herd with a reduction of SCC in the national bulk milk (BMSCC) by more than $15 \%$ over a five period (DairyCo, 2015).

Food safety starts with a healthy animal and the checkpoints implemented by different management systems to control mastitis. For example, the Food Safety and Standards Authority of India (FSSAI), in 2019, drew a 12-point Action Plan to ensure the safety and quality of milk and milk products. The major areas covered through the plan included rigorous surveillance, preventive and corrective action for implementing and monitoring consumer engagement. Furthermore, to effectively implement the Action Plan, FSSAI proposed to organize regional workshops by collaborating with national agencies such as the Department of Animal Husbandry and Dairying (DAHD), National Dairy Development Board (NDDB), National Dairy Research Institute (NDRI) and state Food Safety Departments. Similarly, the dairy sectors in different countries (e.g. Argentina, Netherlands) have also evolved and improved the competitiveness of the dairy chain at the global level. For example, the Ministry of Agroindustry of Argentina with the Direction of Dairy has developed the Argentine Milk Quality Programme to provide accreditation to veterinary professionals for implementing different measures to control milk quality, reducing milking machine contamination, addressing milk quality problems, antibiotic treatment protocols including prevention and control of mastitis (Agroindustria, 2018). To control the zoonotic transmission of any pathogens from farm to dairy products, the FDA established federal guidelines in 1987, requiring the pasteurization of all milk and milk products in the final package form intended for direct human consumption. The most current version of the "Grade A" Pasteurized Milk Ordinance (PMO) outlines provisions for "governing the processing, packaging, and sale of Grade "A" milk and milk products (FDA, 1987). As a result of the various programs implemented by the United States Public Health Service and the FDA, foodborne disease originating from milk has fallen dramatically.

In addition to various management practices, creating awareness among farmers for implementing appropriate management practices is critical to control mastitis. Although, different governments have established action plans and funded various surveillance systems to control the disease, there are prevailing gaps in the socioeconomic strata of the farmers and other stakeholders. This fact has been linked to their physical wellbeing, working efficiency and their decision making ability to tackle the adversaries on a farm. For ex- 
ample, a study reported by Sinha 2014 conducted in the central region of India revealed that approximately $84 \%$ of the farmers' suggested poor sanitation and hygiene as possible major factors that could be influencing the spread of mastitis and further aggravated by the non-availability of proper veterinary services and poor literacy (Sinha, Thombare, \& Mondal, 2014). Furthermore, reports from developed countries like the Netherlands (Huijps, Lam, \& Hogeveen, 2008) and UK (Down, Bradley, Breen, Hudson, \& Green, 2016) also suggested events of transmission due to casualties in management practices or underestimation of the severity of the disease

\section{"One Health One Welfare Strategy" - How Far? How Fast?}

The dairy sector is under tremendous pressure to meet the rise in demand of milk and dairy products, which in turn, relies heavily on different factors such as management and farm resources, land and water availability, feed quality and climate conditions (e.g. dry/wet seasons) that are all interconnected with human society and our planet (Verhees, Malak-Rawlikowska, Stalgiene, Kuipers, \& Klopčič, 2018). However, to accomplish this (or any) ultimatum, humans have always executed a "hook or crook" policy in the name of developments and the eventual casualties have greatly confronted the surrounding nature. It often goes unrecognized until nature retreats with a zoonotic blow that exposes the selfish attitudes of humans of disrespecting the natural biological integrity. As raw milk is a potential and a quick source of zoonosis, the dairy sector, therefore, needs a concerted strategy to prevent the incidence of infection in a farm and transmission to humans through affected dairy products and meat. Taking into account new requirements to prevent zoonosis, four international organizations - FAO, OIE, WHO and United Nations Children's Fund (UNICEF), along with the World Bank and United Nations System Influenza Coordinator (UNSIC), confederated to produce a strategic document (which also stems for the formulation of Manhattan's principles) to give rise to 'One World, One Health' (K \& ZL, 2013) approach. This concept involves experts from various disciplines to recognize the interdependence of humans, animal and health of the ecosystem. It presupposes an international, interdisciplinary and cross-sectoral approach that emphasizes in breaking down barriers among different individuals, agencies and sectors to unleash innovations necessary to face the challenges posed by the emergence and re-emergence of infectious diseases at the interface of human, animals and the ecosystem. 'One Health' approaches in the dairy sector bears in mind the products entering and leaving the dairy farm and the potential impact they could have on humans, animals and the environment (Garcia, 2017). For example, it is critical to ensure the supply and use of good quality water, food with no adulterants and judicious use of antibiotics including proper waste disposal to prevent the unnecessary spread of chemicals and pathogens into the food chain. Of note, it is also vital for the producers to take the necessary steps for the proper disposal of the waste generated reduce contamination.

More recently, an overlapping concept of 'One Welfare' complements 'One World, One Health' by incorporating animal welfare more effectively into a wider policy framework to represent a step forward towards the implementation of strategies to control zoonosis (Jordan \& Lem, 2014). For instance, the OIE animal welfare forum states, "Integrating 'One Welfare' with 'One World, One Health' can strengthen and help to better integrate stakeholder liaison by capturing all relevant issues involving animals and our society in a holistic way " (Garcia, 2017), which is critical to minimize the global impact of pandemics by the zoonotic pathogens. To date, studies have shown that improved animal welfare results in strong herd immunity, thereby protecting the remaining at-risk animals from infection, thus minimizing the spread of infection and usage of antimicrobials for therapeutic intervention (Aarestrup, 2015; Rioja-Lang, Connor, Bacon, Lawrence, \& Dwyer, 2020). The One Welfare Framework includes five key sections that captures the overarching themes, including the connections between animal and human abuse and neglect; the social implications of improved animal welfare; the connection between animal health and welfare; human wellbeing; food security and sustainability within the farming sector; assisted interventions involving animals, humans and the environment and the more holistic aspect of sustainability, including the interconnections between different biodiversities, the environment, animal welfare, and human wellbeing (Garcia, 2017).

One-Health framework is linked to the dairy sector in a way that defines the interconnection between dairy cattle welfare and productivity; between farmer wellbeing and herd welfare or natural resource; the impact 
of conflict or environmental disasters on dairy farmers and their herd (Piotr Pregowski, 2019). It can be safely stated that for the control of zoonosis like mastitis in dairy sectors, it is imperative to integrate OneHealth in different hierarchies of management (Supplementary Table S1). However, it seems clear (from Supplementary Table S1) that the implementations are not "stand-alone" and even a breach in a single ally can bring down the whole agenda. For example, studies in the agricultural sector suggest that the implementation of the management practices depends on the farmer's personality, attitudes, beliefs, values, intentions, skills, knowledge, perceived norms and perceived self-efficacy. All these factors comprise the 'human factor' or 'farmer mindset,' which is assumed to influence the rate of incidence and transmission of mastitis and other zoonosis. Additionally, the aim to effectively control disease like mastitis depends not only on attitude but also on the management style of the farmer as animal welfare has been positively linked to higher productivity (Sinclair, Fryer, \& Phillips, 2019; Skaalsveen, Ingram, \& Urquhart, 2020). This extends to elements linking farmer wellbeing with animal welfare, including farming environment and sustainable production practices. Animal welfare is indicative of a farmer being kind, successful, or abusive, and failing to cope reflecting his wellbeing. In the fourth OIE Global Welfare Conference ("4th OIE Global Conference on Animal Welfare: OIE - World Organisation for Animal Health," 2016), One Welfare concept was promoted by several examples such as (i) reminders of the links between animal welfare and productivity; (ii) understanding the role of animals in supporting human livelihoods, where animals are a source of food, income, social status and cultural identity; and (iii) establishment of silvopastoral farming systems (i.e., trees, shrubs and pasture) that points at improved animal welfare including sustainable farming. More specifically, silvopastoral farming systems promotes more affiliative behavior of animals, greater biodiversity and better ecosystem services, for instance, rapid removal of dung to reduce breeding ground for flies as well as the incidences of diseases such as mastitis (Broom, Galindo, \& Murgueitio, 2013).

During the last decade, One Health concept has proven to be fruitful as the international standard for zoonotic disease control due to the interdisciplinary collaboration approach between professionals from various sectors. However, given the complex interconnections of humans, animals and the environment at different levels, One Health One Welfare is a very broad concept and has ambiguity without a clear definition. As reviewed by Van Herten et al, the concept "functions as a boundary object: by leaving room for interpretation to fit different purposes" (van Herten, Bovenkerk, \& Verweij, 2019). Although, it's application results in the promotion of health of humans, animals and the environment, the underlying concerning cooperation is often a topic of debate since there will be obvious conflicts among the moral values of different integrated sectors and stakeholders. This is evident by the culling of healthy animals to protect public health, which is not a 'mutual-benefit' event for the animals raising questions on the plasticity of the concept, the extent of cooperation in zoonotic disease control and not having a universal definition adds to the complexity of the debate. Therefore, One Health approach requires strict necessary steps to define a set of areas and goals for a conceptual framework to checkmate at the very beginning of the spillover. For example, developing strategies in animal-related areas could include building economic growth to address a range of social needs such as education, health, social protection and job opportunities. Similarly, tackling climate change and environmental protection could be a significant step forward towards the implementation of One Health approach. But the biggest dilemma is if (and when) it is enough to facilitate stakeholders across disciplines to work together towards a common goal for improving the welfare of all. The successful implementation and improvements of different animal welfare standards and policies will facilitate the integration of various health care providers for the benefit of the society. Considering all the opportunities and obstacles together (Fig. 2), it is safe to say that implementing a 'One World One Health One Welfare' approach can serve to significantly 'improve animal-human welfare (and vice versa) and prevent the emergence of zoonotic pathogens.

\section{Integrating Omics Technologies - All-in-One Well}

The integrated approach of 'One Health, One Welfare' in veterinary medicine is necessary to control and spread of zoonotic diseases. To date, all 'omics' - genomics, transcriptomics, proteomics and metabolomics have individually contributed to understanding the pathophysiology of mastitis. However, it is quite improbable that any singular 'omics' field can be the key piece to solve the puzzle of biological phenomena in 
animal bioscience. Thus, to better understand the 'bigger picture' of 'One Health, One Welfare' concept, it is imperative to use a combinatorial approach of multi-omics technologies with a 'non-hypothesis' driven approach to control mastitis (Fig. 3). Multi-omics technologies offer newer opportunities to monitor and control cross-species disease jump and, in particular, allow scientists to quickly detect the presence of pertinent characteristics such as virulence determinants and drug resistance exhibited by a pathogen including limitations (as listed in Fig. 3) that need to be addressed for its successful implementation.

Spillover transmission is possible in successive events when a pathogen establishes a cross species infection. Implementing genomic cross-species surveillance (One Health) would enable early detection of pathogens and their transmission within and between species. Nevertheless, epidemiological analyses to trace the transmission between animal populations and/or between animals and humans are rarely conducted. Thus, a pertinent question arises as to how a cross-species (One Health) approach could benefit both animal and human populations. Recently, pathogen genomics is beginning to improve the face of disease diagnosis and genomic methods and DNA-based techniques such as PCR, RT-PCR and Randomly Amplified Polymorphic DNA (RADP) have been used to characterize pathogens phylogenetically and events of host switch in mastitis (Franco-Duarte et al., 2019; Yang, Hu, Chen, Ding, \& Zhou, 2018). Nevertheless, lack of sufficient discriminatory power still prevails when multiple strains are together, suggesting widespread contagiousness, while better discriminatory methods would have told a different story. Furthermore, the paucity of specific genetic markers in mastitis is met with an increase in demand to identify and justify their evaluation in different biological and pathogenic processes, or pharmacologic responses for therapeutic intervention as a step forward to implement One Health approach. Thereupon, several researchers have successfully utilized two important methodologies, QTL (Quantitative Trait Loci) analysis and the GWAS (Genome Wide Association Study), for example, to develop Cattle Quantitative Trait Locus Database (Cattle QTLdb) archiving over 130,400 QTLs/associations (Hu, Park, \& Reecy, 2019) and identification of 1297 QTLs for bovine CM (Klungland et al., 2001). These techniques along with bioinformatics have significantly contributed in identifying genetic markers predisposing an animal to mastitis, including potential newer targets for mastitis therapy.

During mastitis, the complex biological massacre turns on and off genes to produce sets of transcripts that generate a comprehensive picture qualitatively and quantitatively at the different progressive stage of the infection. For example, in the past several years, people have exploited transcriptomics to study mRNA markers (e.g., TLRs, anti-microbial peptides, cytokines haptoglobin and Farnesyl diphosphate synthase) from mammary tissue in response to different causative organisms (e.g. S. uberis, S. aureus, E. coli) of mastitis (Ju et al., 2020; Kosciuczuk et al., 2017; Swanson et al., 2009). More recently, investigation of miRNA profiles between bovine mammary glands infected with $S$. aureus and $E$. coli resulted in the identification of 1838 different miRNAs of which over 190 differentially expressed miRNA were identical in both infections (Luoreng, Wang, Mei, \& Zan, 2018) and needed further validation as potential markers for the early detection of bovine mastitis. Although promising, use of transcriptomics in the field of bovine mastitis is still in its nascent stage and long way to go before we understand its extent of simplicity or complexity to find a transcript biomarker that would be clinically implementable.

Animal and human health are intertwined aspects of the One-Health concept; thus it is critical to define the connecting wheels (genomics, transcriptomics, proteomics, and metabolomics) to the axle (diagnosis of bovine mastitis) that are important for producers and consumers, to monitor and assess the welfare of production animals effectively. In addition to genomics and transcriptomics, High throughput proteomics has contributed significantly to the biomarker discovery in health and mastitis which have contributed to the development of databases like Bovine PeptideAtlas, a database created within the PeptideAtlas framework (Bislev et al., 2012) and more recently, BoMiProt, a Bovine Milk Protein Database, an in-depth reference database on the existing literature on bovine milk and possible information gaps in dairy research (Maity, Bhat, Giri, \& Ambatipudi, 2020). The traditional proteomic approach has been used to separate complex protein samples by 2-dimensional gel electrophoresis followed by identification of whey proteins using matrix-assisted laser desorption ionization (MALDI) MS in mastitis (Boehmer, Bannerman, Shefcheck, \& Ward, 2008). However, a major limitation has been the identification of low abundant proteins, which may be functionally 
important, to understand the pathophysiology of mastitis. Subsequently, separation of protein using single reversed-phase liquid chromatography (LC) coupled tandem MS provided an indispensable advantage for the separation of complex proteome to facilitate protein identification and quantitation. Subsequently, a wide dynamic range and extreme sensitivity of Multidimensional Protein Identification Technology (MudPIT) with pre-fractionation resulted in enhanced detection, coverage, and biological inference of protein associated with health and disease (Kislinger, Gramolini, MacLennan, \& Emili, 2005). However, the only current limitation of MudPIT in different laboratories is the lack of sufficient computing ability to handle huge data generated from proteomic analysis. More recently, several LC-based quantitative proteomics methods such as labeled (isobaric tag for relative and absolute quantitation; iTRAQ) and Tandem Mass Tags;TMT), or label-free quantitation (spectral counts) methodologies have been used to investigate the pathophysiology of bovine mastitis and identify potential markers for early diagnosis (Huang et al., 2014; Mudaliar et al., 2016; Zhang et al., 2018). Apart from the identification of specific marker candidates, proteomics has also contributed to the understanding of disease pathogenesis, herd management, effect of various stress inducers on animal welfare and productivity (Eckersall, de Almeida, \& Miller, 2012). Although proteomics has been an important investigating tool to monitor animal stress and welfare, objective and quantitative laboratory markers are still lacking to date. Nevertheless, there has been an increase in awareness of the applicability of different proteomic approaches to characterize proteins produced by farm animals to establish a connection between animal science and technological-based proteomics. The application of proteomics for real-life problems combined with the integration of basic and clinical research will further promote the field and expected to play an increasing role in farm animal proteomics to understand better all aspects related to animal stress and welfare including the economic impact of variation in production of livestock and aquaculture systems.

Multiple omics measurements have been associated with the prognosis of several human diseases (e.g. cancer, AIDS, Parkinson's) (Hasin, Seldin, \& Lusis, 2017; Sun \& Hu, 2016), and it is conceivable that such powerful and sensitive data-driven paradigms will be a part of veterinary medicine and research to facilitate clinical diagnosis and treatment. More recently, metabolomics has also become an important technique to investigate animal health, production, and food safety. To date, several metabolomic studies have been performed in cattle leading to the development of the Bovine Metabolome Database (BMDB), (http://www.cowmetdb.ca/) comprising information on metabolites of dairy and beef cattle from blood, meat, urine, milk and ruminal fluid (Hailemariam et al., 2014). However, only a few studies have thus far reported the use of metabolomics in mastitis research with the application of Gas Chromatography (GC)-MS to differentiate milk between healthy and mastitis to identify the pathogenic sources of volatile metabolites (Tong, Zhang, Zhang, Xiong, \& Jiang, 2019). More recently, Sundekilde et al. used NMR spectroscopy to compare metabolite profiles of milk with higher and lower SCC, resulting in the identification and higher abundance of lactate, acetate, isoleucine, butyrate and BHBA in samples with high SCC, while lactose, hippurate and fumarate were detected with in lower concentrations (Sundekilde, Poulsen, Larsen, \& Bertram, 2013). Similarly, milk lipidome analysis using LC-MS/MS investigated the role of oxylipids in bovine coliform mastitis and mastitis caused by S. uberis (Mavangira, Mangual, Gandy, \& Sordillo, 2016; Ryman et al., 2015). Although, using global untargeted metabolomics to decipher information in livestock disease is slowly gaining pace, there are still many gaps to exploit in several areas of animal health, nutrition, production, reproduction, physiology and human health (livestock models used for human health studies), which comprise a One Health One Welfare approach.

One Health is a holistic approach that focuses and combines data collected from different omics technologies. Although the idea of integrating multi-omics for a One-Health approach sounds promising, there lies a persistent challenge of collaboration across various disciplines for a strategic solution to solve a complex disease like mastitis that demands management in several hierarchies. No one research group on their own can handle multi-scale omics data generation, development of analytical methodology, adaptation of those methods to a specific disease, and functional follow-up, let alone repeating this process for multiple parameters as required for One Health approach and integration. Thus, it augurs a coordinated effort between basic science and clinical researchers to design omics studies to generate meaningful and applicable translational medicine data to control and tackle a global health problem of mastitis in livestock. 


\section{Conclusion}

Bovine mastitis is a zoonotic disease that will not create a disaster with a bang but will be associated with "creeping normality" to the global economy. The propensity of the zoonotic pathogens to evolve with their rapidly changing environment creates troubling circumstances for future treatment and management strategies of emerging pathogens. More specifically, the potentiality of the pathogen to succeed in hiding inside for years leads to an asymptomatic and chronic stage of the disease, which is an icing on top of all. Therefore, One Health approach, which enables to establish a long-term, sustainable, and diagnostic modalities as close to the local level is the only key step to rapidly identifying and alerting public health authorities and avoiding a possible global pandemic. However, regardless of the technology used and the scientific capacities developed, failure to engage and build trust with local political and visionary leaders, traditional health workers, and community groups in disease detection and control would delay diagnosis and response, with potentially disastrous consequences. The lack of communication between different stakeholders has led to the rapid spread of the novel Coronavirus crisis of 2019-2020, which is a stark warning that zoonotic threats, novel or known, symptomatic or asymptomatic and chronic or acute can emerge and quickly threaten global health security. It is important to avoid a repeat of this scenario and halt whatever the next global pandemic could emerge at the animal-human interface, with an initial spillover to local communities. Environmental, veterinary, and human health sectors must work in close collaboration to better our understanding of zoonotic disease ecology and prevention. Due to the rise in rate of contact between humans and cattle, as well as their global movement, establishing a strong epidemiological framework is critical to study and monitor the pathogens on a global scale.

\section{ACKNOWLEDGMENT}

This work was supported by the Department of Science and Technology (Grant No: ECR/2015/000179) Govt. of India. S.M. was supported by the Ministry of Human Resource Development, Govt. of India.

\section{DECLARATION}

\section{Conflict of Interest Statement}

The authors declare no conflict of interest.

\section{Availability of Data}

Data sharing is not applicable as this is a review article and no new data were created or analyzed in this study.

\section{REFERENCES}

4th OIE Global Conference on Animal Welfare: OIE - World Organisation for Animal Health. (2016). Retrieved April 12, 2020, from https://webcache.googleusercontent.com/search?q=cache:ZKdrUNgjVxMJ:https://www.oie.int/for-themedia/press-releases $/ 2016 / 4$ th-oie-global-conference-on-animal-welfare $/+\& c d=1 \&$ hl $=$ en\&ct=clnk\&gl=in

Aarestrup, F. M. (2015). The livestock reservoir for antimicrobial resistance: A personal view on changing patterns of risks, effects of interventions and the way forward. Philosophical Transactions of the Royal Society B: Biological Sciences , 370 (1670), 20140085. https://doi.org/10.1098/rstb.2014.0085

Agroindustria, M. de. (2018). Gobierno de la Nación (2018) Programa Argentino de Calidad de Leche. Retrieved April 11, 2020, from https://www.magyp.gob.ar/sitio/areas/ss_lecheria/

Andersen, H. J., Pedersen, L. H., Aarestrup, F. M., \& Chriél, M. (2003). Evaluation of the surveillance program of Streptococcus agalactiae in Danish dairy herds. Journal of Dairy Science ,86 (4), 1233-1239. https://doi.org/10.3168/jds.S0022-0302(03)73707-2

Anjum, M. F., Marco-Jimenez, F., Duncan, D., Marín, C., Smith, R. P., \& Evans, S. J. (2019, September 12). Livestock-Associated Methicillin-Resistant Staphylococcus aureus From Animals and Animal Products 
in the UK. Frontiers in Microbiology, Vol. 10, p. 2136. https://doi.org/10.3389/fmicb.2019.02136

Bardiau, M., Yamazaki, K., Duprez, J. N., Taminiau, B., Mainil, J. G., \& Ote, I. (2013). Genotypic and phenotypic characterization of methicillin-resistant Staphylococcus aureus (MRSA) isolated from milk of bovine mastitis. Letters in Applied Microbiology , 57 (3), 181-186. https://doi.org/10.1111/lam.12099

Berry, E. A., \& Hillerton, J. E. (2002). The effect of selective dry cow treatment on new intramammary infections. Journal of Dairy Science , 85 (1), 112-121. https://doi.org/10.3168/jds.S0022-0302(02)74059-9

Bisharat, N., Crook, D. W., Leigh, J., Harding, R. M., Ward, P. N., Coffey, T. J., . . Jones, N. (2004). Hyperinvasive neonatal group B streptococcus has arisen from a bovine ancestor. Journal of Clinical Microbiology , 42 (5), 2161-2167. https://doi.org/10.1128/jcm.42.5.2161-2167.2004

Bislev, S. L., Deutsch, E. W., Sun, Z., Farrah, T., Aebersold, R., Moritz, R. L., .. Codrea, M. C. (2012). A Bovine PeptideAtlas of milk and mammary gland proteomes. Proteomics , 12 (18), 2895-2899. https://doi.org/10.1002/pmic.201200057

Boehmer, J. L., Bannerman, D. D., Shefcheck, K., \& Ward, J. L. (2008). Proteomic analysis of differentially expressed proteins in bovine milk during experimentally induced Escherichia coli mastitis. Journal of Dairy Science , 91 (11), 4206-4218. https://doi.org/10.3168/jds.2008-1297

Booth, B. W., Boulanger, C. A., Anderson, L. H., \& Smith, G. H. (2011). The normal mammary microenvironment suppresses the tumorigenic phenotype of mouse mammary tumor virus-neu-transformed mammary tumor cells. Oncogene , 30 (6), 679-689. https://doi.org/10.1038/onc.2010.439

Boss, R., Cosandey, A., Luini, M., Artursson, K., Bardiau, M., Breitenwieser, F., ... Graber, H. U. (2016). Bovine Staphylococcus aureus: Subtyping, evolution, and zoonotic transfer. Journal of Dairy Science, 99 (1), 515-528. https://doi.org/10.3168/jds.2015-9589

Broom, D. M., Galindo, F. A., \& Murgueitio, E. (2013, September 25). Sustainable, efficient livestock production with high biodiversity and good welfare for animals. Proceedings of the Royal Society B: Biological Sciences , Vol. 280, p. 20132025. https://doi.org/10.1098/rspb.2013.2025

Capuco, A. V., Wood, D. L., Bright, S. A., Miller, R. H., \& Bitman, J. (1990). Regeneration of Teat Canal Keratin in Lactating Dairy Cows.Journal of Dairy Science , 73 (7), 1745-1750. https://doi.org/10.3168/jds.S0022-0302(90)78851-0

Capuco, A. V, Bright, S. A., Pankey, J. W., Wood, D. L., Miller, R. H., \& Bitman, J. (1992). Increased susceptibility to intramammary infection following removal of teat canal keratin. Journal of Dairy Science , 75 (8), 2126-2130. https://doi.org/10.3168/jds.s0022-0302(92)77972-7

Chen, C.-J., Lauderdale, T.-L. Y., Lu, C.-T., Chuang, Y.-Y., Yang, C.-C., Wu, T.-S., ... Huang, Y.-C. (2018). Clinical and molecular features of MDR livestock-associated MRSA ST9 with staphylococcal cassette chromosome mecXII in humans. The Journal of Antimicrobial Chemotherapy , 73 (1), 33-40. https://doi.org/10.1093/jac/dkx357

Chen, S. L. (2019). Genomic insights into the distribution and evolution of group B streptococcus. Frontiers in Microbiology ,10 (JUN), 1447. https://doi.org/10.3389/fmicb.2019.01447

Cobo-Angel, C. G., Jaramillo-Jaramillo, A. S., Palacio-Aguilera, M., Jurado-Vargas, L., Calvo-Villegas, E. A., Ospina-Loaiza, D. A., ... Ceballos-Marquez, A. (2019a). Potential group B Streptococcus interspecies transmission between cattle and people in Colombian dairy farms. Scientific Reports , 9 (1). https://doi.org/10.1038/s41598-019-50225-w

Cobo-Angel, C. G., Jaramillo-Jaramillo, A. S., Palacio-Aguilera, M., Jurado-Vargas, L., Calvo-Villegas, E. A., Ospina-Loaiza, D. A., .. Ceballos-Marquez, A. (2019b). Potential group B Streptococcus interspecies transmission between cattle and people in Colombian dairy farms. Scientific Reports , 9 (1), 14025. https://doi.org/10.1038/s41598-019-50225-w 
DairyCo. (2015). DairyCo Mastitis Control Plan. Retrieved April 11, 2020, from http://dairy.ahdb.org.uk/news/news-archive/2015/\#.XpFyPP0zbIU

Devriese, L. A., \& Hommez, J. (1975). Epidemiology of methicillin resistant Staphylococcus aureus in dairy herds. Research in Veterinary Science , 19 (1), 23-27. https://doi.org/10.1016/s0034-5288(18)33549-5

Dhup, V., Kearns, A. M., Pichon, B., \& Foster, H. A. (2015). First report of identification of livestockassociated MRSA ST9 in retail meat in England. Epidemiology and Infection , 143 (14), 2989-2992. https://doi.org/10.1017/S0950268815000126

Dogan, B., Schukken, Y. H., Santisteban, C., \& Boor, K. J. (2005). Distribution of serotypes and antimicrobial resistance genes among Streptococcus agalactiae isolates from bovine and human hosts. Journal of Clinical Microbiology , 43 (12), 5899-5906. https://doi.org/10.1128/JCM.43.12.5899-5906.2005

Down, P. M., Bradley, A. J., Breen, J. E., Hudson, C. D., \& Green, M. J. (2016). Current management practices and interventions prioritised as part of a nationwide mastitis control plan. Veterinary Record ,178 (18), 449. https://doi.org/10.1136/vr.103203

Dufour, S., Labrie, J., \& Jacques, M. (2019). The Mastitis Pathogens Culture Collection. Microbiology Resource Announcements ,8 (15). https://doi.org/10.1128/MRA.00133-19

Eckersall, P. D., de Almeida, A. M., \& Miller, I. (2012, July 19). Proteomics, a new tool for farm animal science. Journal of Proteomics, Vol. 75, pp. 4187-4189. https://doi.org/10.1016/j.jprot.2012.05.014

Farm, I., \& Network, C. (2011). Dairy Report 2011 r ze Pfi .

FDA. (1987). Final Rule on Raw Milk .

Ferreira, J. P., Anderson, K. L., Correa, M. T., Lyman, R., Ruffin, F., Reller, L. B., \& Fowler, V. G. (2011). Transmission of mrsa between companion animals and infected human patients presenting to outpatient medical care facilities. PLoS ONE , 6 (11), e26978. https://doi.org/10.1371/journal.pone.0026978

Fitzgerald, J. R. (2012, March). Human origin for livestock-associated methicillin-resistant Staphylococcus aureus. MBio, Vol. 3, pp. e00082-12. https://doi.org/10.1128/mBio.00082-12

Franco-Duarte, R., Černáková, L., Kadam, S., Kaushik, K. S., Salehi, B., Bevilacqua, A., .. Rodrigues, C. F. (2019, May 1). Advances in chemical and biological methods to identify microorganisms-from past to present. Microorganisms, Vol. 7. https://doi.org/10.3390/microorganisms7050130

García-Álvarez, L., Holden, M. T. G., Lindsay, H., Webb, C. R., Brown, D. F. J., Curran, M. D., ... Holmes, M. A. (2011a). Meticillin-resistant Staphylococcus aureus with a novel mecA homologue in human and bovine populations in the UK and Denmark: A descriptive study. The Lancet Infectious Diseases , 11 (8), 595-603. https://doi.org/10.1016/S1473-3099(11)70126-8

García-Álvarez, L., Holden, M. T. G., Lindsay, H., Webb, C. R., Brown, D. F. J., Curran, M. D., ... Holmes, M. A. (2011b). Meticillin-resistant Staphylococcus aureus with a novel mecA homologue in human and bovine populations in the UK and Denmark: A descriptive study. The Lancet Infectious Diseases , 11 (8), 595-603. https://doi.org/10.1016/S1473-3099(11)70126-8

Garcia, R. (2017). One Welfare': A framework to support the implementation of OIE animal welfare standards. Bull. L'OIE ,2017, 3-8.

Green, M. J., Bradley, A. J., Medley, G. F., \& Browne, W. J. (2007). Cow, farm, and management factors during the dry period that determine the rate of clinical mastitis after calving. Journal of Dairy Science, 90 (8), 3764-3776. https://doi.org/10.3168/jds.2007-0107

Gresham, H. D., Lowrance, J. H., Caver, T. E., Wilson, B. S., Cheung, A. L., \& Lindberg, F. P. (2000). Survival of Staphylococcus aureus Inside Neutrophils Contributes to Infection. The Journal of Immunology ,164 (7), 3713-3722. https://doi.org/10.4049/jimmunol.164.7.3713 
Gushulak, B. D., \& MacPherson, D. W. (2004). Globalization of Infectious Diseases: The Impact of Migration. Clinical Infectious Diseases , 38 (12), 1742-1748. https://doi.org/10.1086/421268

Haas, P.-J., de Haas, C. J. C., Kleibeuker, W., Poppelier, M. J. J. G., van Kessel, K. P. M., Kruijtzer, J. A. W., .. van Strijp, J. A. G. (2004). N-Terminal Residues of the Chemotaxis Inhibitory Protein of Staphylococcus aureus Are Essential for Blocking Formylated Peptide Receptor but Not C5a Receptor . The Journal of Immunology ,173 (9), 5704-5711. https://doi.org/10.4049/jimmunol.173.9.5704

Hailemariam, D., Mandal, R., Saleem, F., Dunn, S. M., Wishart, D. S., \& Ametaj, B. N. (2014). Identification of predictive biomarkers of disease state in transition dairy cows. Journal of Dairy Science ,97 (5), 2680-2693. https://doi.org/10.3168/jds.2013-6803

Hasin, Y., Seldin, M., \& Lusis, A. (2017, May 5). Multi-omics approaches to disease. Genome Biology, Vol. 18. https://doi.org/10.1186/s13059-017-1215-1

Hata, E., Katsuda, K., Kobayashi, H., Uchida, I., Tanaka, K., \& Eguchi, M. (2010). Genetic variation among Staphylococcus aureus strains from bovine milk and their relevance to methicillin-resistant isolates from humans. Journal of Clinical Microbiology , 48 (6), 2130-2139. https://doi.org/10.1128/JCM.01940-09

Hensen, S. M., Pavičić, M. J. A. M. P., Lohuis, J. A. C. M., \& Poutrel, B. (2000). Use of bovine primary mammary epithelial cells for the comparison of adherence and invasion ability of Staphylococcus aureus strains. Journal of Dairy Science , 83 (3), 418-429. https://doi.org/10.3168/jds.S0022-0302(00)74898-3

Hu, Z.-L., Park, C. A., \& Reecy, J. M. (2019). Building a livestock genetic and genomic information knowledgebase through integrative developments of Animal QTLdb and CorrDB. Nucleic Acids Research ,47 (D1), D701-D710. https://doi.org/10.1093/nar/gky1084

Huang, J., Luo, G., Zhang, Z., Wang, X., Ju, Z., Qi, C., .. Zhong, J. (2014). ITRAQ-proteomics and bioinformatics analyses of mammary tissue from cows with clinical mastitis due to natural infection with Staphylococci aureus. BMC Genomics , 15 (1), 839. https://doi.org/10.1186/1471-2164-15-839

Huijps, K., Lam, T. J. G. M., \& Hogeveen, H. (2008). Costs of mastitis: Facts and perception. Journal of Dairy Research , 75 (1), 113-120. https://doi.org/10.1017/S0022029907002932

Jordan, T., \& Lem, M. (2014). One health, one welfare: Education in practice veterinary students' experiences with community veterinary outreach. Canadian Veterinary Journal , 55 (12), 1203-1206.

Ju, Z., Jiang, Q., Wang, J., Wang, X., Yang, C., Sun, Y., ... Huang, J. (2020). Genome-wide methylation and transcriptome of blood neutrophils reveal the roles of DNA methylation in affecting transcription of protein-coding genes and miRNAs in E. coli-infected mastitis cows. BMC Genomics , 21 (1), 102. https://doi.org/10.1186/s12864-020-6526-z

Juhász-Kaszanyitzky, É., Jánosi, S., Somogyi, P., Dán, Á., Van Der Graaf-van Bloois, L., Van Duijkeren, E., \& Wagenaar, J. A. (2007). MRSA transmission between cows and humans. Emerging Infectious Diseases, 13 (4), 630-632. https://doi.org/10.3201/eid1304.060833

K, L., \& ZL, B. (2013). Operationalizing the One Health approach: the global governance challenges. - PubMed - NCBI. Health Policy Plan, 27 (7), 778-785. Retrieved from https://www.ncbi.nlm.nih.gov/pubmed/23221123

Kayansamruaj, P., Soontara, C., Unajak, S., Dong, H. T., Rodkhum, C., Kondo, H., ... Areechon, N. (2019). Comparative genomics inferred two distinct populations of piscine pathogenic Streptococcus agalactiae, serotype Ia ST7 and serotype III ST283, in Thailand and Vietnam.Genomics , 111 (6), 1657-1667. https://doi.org/10.1016/j.ygeno.2018.11.016

Kislinger, T., Gramolini, A. O., MacLennan, D. H., \& Emili, A. (2005). Multidimensional protein identification technology (MudPIT): Technical overview of a profiling method optimized for the comprehensive 
proteomic investigation of normal and diseased heart tissue. Journal of the American Society for Mass Spectrometry , 16 (8), 1207-1220. https://doi.org/10.1016/j.jasms.2005.02.015

Klungland, H., Sabry, A., Heringstad, B., Olsen, H. G., Gomez-Raya, L., Våge, D. I., .. Lien, S. (2001). Quantitative trait loci affecting clinical mastitis and somatic cell count in dairy cattle.Mammalian Genome , 12 (11), 837-842. https://doi.org/10.1007/s00335001-2081-3

Kosciuczuk, E. M., Lisowski, P., Jarczak, J., Majewska, A., Rzewuska, M., Zwierzchowski, L., \& Bagnicka, E. (2017). Transcriptome profiling of Staphylococci-infected cow mammary gland parenchyma. BMC Veterinary Research , 13 (1), 161. https://doi.org/10.1186/s12917-017-1088-2

Landes, M., Cessna, J., Kuberka, L., \& Jones, K. (2017). India's dairy sector: structure, performance, and prospects. A Report from the Economic Research Service , 1-47.

Layton, D. S., Choudhary, A., \& Bean, A. G. D. (2017). Breaking the chain of zoonoses through biosecurity in livestock. Vaccine ,35 (44), 5967-5973. https://doi.org/10.1016/j.vaccine.2017.07.110

Lee, J. H. (2003). Methicillin (Oxacillin)-Resistant Staphylococcus aureus Strains Isolated from Major Food Animals and their Potential Transmission to Humans. Applied and Environmental Microbiology ,69 (11), 6489-6494. https://doi.org/10.1128/AEM.69.11.6489-6494.2003

Leitner, G., Lavon, Y., Merin, U., Jacoby, S., Blum, S. E., Krifucks, O., \& Silanikove, N. (2019). Milk quality and milk transformation parameters from infected mammary glands depends on the infecting bacteria species. PLoS ONE , 14 (7). https://doi.org/10.1371/journal.pone.0213817

Lewis, H. C., Mølbak, K., Reese, C., Aarestrup, F. M., Selchau, M., Sørum, M., \& Skov, R. L. (2008). Pigs as Source of Methicillin-Resistant Staphylococcus aureus CC398 Infections in Humans, Denmark . Emerging Infectious Diseases , 14 (9), 1383-1389. https://doi.org/10.3201/eid1409.071576

Liu, G. Y., Essex, A., Buchanan, J. T., Datta, V., Hoffman, H. M., Bastian, J. F., .. Nizet, V. (2005). Staphylococcus aureus golden pigment impairs neutrophil killing and promotes virulence through its antioxidant activity. Journal of Experimental Medicine ,202 (2), 209-215. https://doi.org/10.1084/jem.20050846

Liu, W., Røder, H. L., Madsen, J. S., Bjarnsholt, T., Sørensen, S. J., \& Burmølle, M. (2016, August 31). Interspecific bacterial interactions are reflected in multispecies biofilm spatial organization. Frontiers in Microbiology, Vol. 7, p. 1366. https://doi.org/10.3389/fmicb.2016.01366

Lucey, J. A. (2015). Raw Milk Consumption: Risks and Benefits.Nutrition Today , 50 (4), 189-193. https://doi.org/10.1097/NT.0000000000000108

Luoreng, Z. M., Wang, X. P., Mei, C. G., \& Zan, L. Sen. (2018). Comparison of microRNA profiles between bovine mammary glands infected with Staphylococcus aureus and Escherichia coli. International Journal of Biological Sciences , 14 (1), 87-99. https://doi.org/10.7150/ijbs.22498

Lyhs, U., Kulkas, L., Katholm, J., Waller, K. P., Saha, K., Tomusk, R. J., \& Zadoks, R. N. (2016a). Streptococcus agalactiae serotype IV in humans and cattle, Northern Europe. Emerging Infectious Diseases ,22 (12), 2097-2103. https://doi.org/10.3201/eid2212.151447

Lyhs, U., Kulkas, L., Katholm, J., Waller, K. P., Saha, K., Tomusk, R. J., \& Zadoks, R. N. (2016b). Streptococcus agalactiae serotype IV in humans and cattle, Northern Europe. Emerging Infectious Diseases ,22 (12), 2097-2103. https://doi.org/10.3201/eid2212.151447

Lyhs, U., Kulkas, L., Katholm, J., Waller, K. P., Saha, K., Tomusk, R. J., \& Zadoks, R. N. (2016c). Streptococcus agalactiae serotype IV in humans and cattle, Northern Europe. Emerging Infectious Diseases ,22 (12), 2097-2103. https://doi.org/10.3201/eid2212.151447

Lyhs, U., Kulkas, L., Katholm, J., Waller, K. P., Saha, K., Tomusk, R. J., \& Zadoks, R. N. (2016d). Streptococcus agalactiae serotype IV in humans and cattle, Northern Europe. Emerging Infectious Diseases ,22 (12), 2097-2103. https://doi.org/10.3201/eid2212.151447 
Mahanti, A., Joardar, S. N., Bandyopadhyay, S., Banerjee, J., Ghosh, S., Batabyal, K., . . Samanta, I. (2020). Characterization of methicillin-resistant and enterotoxins producing Staphylococcus aureus in bovine milk in India. Journal of Agriculture and Food Research , 2 , 100017. https://doi.org/10.1016/j.jafr.2019.100017

Maity, S., Bhat, A. H., Giri, K., \& Ambatipudi, K. (2020). BoMiProt: A database of bovine milk proteins. Journal of Proteomics ,215 , 103648. https://doi.org/10.1016/j.jprot.2020.103648

Manning, S. D., Springman, A. C., Million, A. D., Milton, N. R., McNamara, S. E., Somsel, P. A., ... Davies, H. D. (2010). Association of group B Streptococcus colonization and bovine exposure: A prospective cross-sectional cohort study. PLoS ONE , 5 (1). https://doi.org/10.1371/journal.pone.0008795

Martinez, G., Harel, J., Higgins, R., Lacouture, S., Daignault, D., \& Gottschalk, M. (2000). Characterization of Streptococcus agalactiae isolates of bovine and human origin by randomly amplified polymorphic DNA analysis. Journal of Clinical Microbiology, 38 (1), 71-78.

Mavangira, V., Mangual, M. J., Gandy, J. C., \& Sordillo, L. M. (2016). 15-F2t-Isoprostane Concentrations and Oxidant Status in Lactating Dairy Cattle with Acute Coliform Mastitis. Journal of Veterinary Internal Medicine , 30 (1), 339-347. https://doi.org/10.1111/jvim.13793

Mazzariol, S., Corrò, M., Tonon, E., Biancani, B., Centelleghe, C., \& Gili, C. (2018). Death Associated to Methicillin Resistant Staphylococcus aureus ST8 Infection in Two Dolphins Maintained Under Human Care, Italy. Frontiers in Immunology, 9 (NOV), 2726. https://doi.org/10.3389/fimmu.2018.02726

Mudaliar, M., Tassi, R., Thomas, F. C., McNeilly, T. N., Weidt, S. K., McLaughlin, M., ... Zadoks, R. N. (2016). Mastitomics, the integrated omics of bovine milk in an experimental model of: Streptococcus uberis mastitis: 2. Label-free relative quantitative proteomics. Molecular BioSystems , 12 (9), 2748-2761. https://doi.org/10.1039/c6mb00290k

NAAS. (2013). Mastitis Management in Dairy Animals . Retrieved from http://www.naasindia.org

NMC. (2016). Recommended Mastitis Control Program. NaThe National Mastitis Council. Disponivel Em Www.Nmconline.Org/Docs/NMCchecklistNA.Pdf. , (April 9), 1-2.

O'Neill, E., Pozzi, C., Houston, P., Smyth, D., Humphreys, H., Robinson, D. A., \& O'Gara, J. P. (2007). Association between methicillin susceptibility and biofilm regulation in Staphylococcus aureus isolates from device-related infections. Journal of Clinical Microbiology ,45 (5), 1379-1388. https://doi.org/10.1128/JCM.02280-06

Oliver, S. P., Jayarao, B. M., \& Almeida, R. A. (2005, June). Foodborne pathogens in milk and the dairy farm environment: Food safety and public health implications. Foodborne Pathogens and Disease, Vol. 2, pp. 115-129. https://doi.org/10.1089/fpd.2005.2.115

Ouweltjes, W., Beerda, B., Windig, J. J., Calus, M. P. L., \& Veerkamp, R. F. (2007). Effects of management and genetics on udder health and milk composition in dairy cows. Journal of Dairy Science, 90 (1), 229-238. https://doi.org/10.3168/jds.S0022-0302(07)72624-3

Paterson, G. K., Larsen, J., Harrison, E. M., Larsen, A. R., Morgan, F. J., Peacock, S. J., .. Holmes, M. A. (2012). First detection of livestock-associated meticillin-resistant Staphylococcus Aureus CC398 in bulk tank milk in the United Kingdom, January to July 2012.Eurosurveillance , 17 (50). https://doi.org/10.2807/ese.17.50.20337-en

Paterson, G. K., Morgan, F. J. E., Harrison, E. M., Peacock, S. J., Parkhill, J., Zadoks, R. N., \& Holmes, M. A. (2014). Prevalence and properties of mecc methicillin-resistant Staphylococcus aureus (mrsa) in bovine bulk tank milk in great britain. Journal of Antimicrobial Chemotherapy , 69 (3), 598-602. https://doi.org/10.1093/jac/dkt417

Paterson, Gavin K., Harrison, E. M., \& Holmes, M. A. (2014, January). The emergence of 
mecC methicillin-resistant Staphylococcus aureus.Trends in Microbiology , Vol. 22, pp. 42-47. https://doi.org/10.1016/j.tim.2013.11.003

Piepers, S., De Meulemeester, L., De Kruif, A., Opsomer, G., Barkema, H. W., \& De Vliegher, S. (2007). Prevalence and distribution of mastitis pathogens in subclinically infected dairy cows in Flanders, Belgium.Journal of Dairy Research , 74 (4), 478-483. https://doi.org/10.1017/S0022029907002841

Piotr Pregowski, M. (2019). One Welfare: A Framework to Improve Animal Welfare and Human Well-being. Anthrozoös , 32 (6), 837-839. https://doi.org/10.1080/08927936.2019.1673070

Rainard, P., Cunha, P., \& Gilbert, F. B. (2016). Innate and adaptive immunity synergize to trigger inflammation in the mammary gland.PLoS ONE , 11 (4). https://doi.org/10.1371/journal.pone.0154172

Rioja-Lang, F. C., Connor, M., Bacon, H. J., Lawrence, A. B., \& Dwyer, C. M. (2020). Prioritization of Farm Animal Welfare Issues Using Expert Consensus. Frontiers in Veterinary Science , 6 , 495. https://doi.org/10.3389/fvets.2019.00495

Rodriguez-Morales, A. J., Bonilla-Aldana, D. K., Balbin-Ramon, G. J., Rabaan, A. A., Sah, R., PanizMondolfi, A., ... Esposito, S. (2020). History is repeating itself, a probable zoonotic spillover as a cause of an epidemic: the case of 2019 novel Coronavirus. Le Infezioni in Medicina , 28 (1), 3-5. Retrieved from http://www.ncbi.nlm.nih.gov/pubmed/32009128

Rosini, R., \& Margarit, I. (2015). Biofilm formation by Streptococcus agalactiae: Influence of environmental conditions and implicated virulence factor. Frontiers in Cellular and Infection Microbiology, Vol. 5. https://doi.org/10.3389/fcimb.2015.00006

Ryman, V. E., Pighetti, G. M., Lippolis, J. D., Gandy, J. C., Applegate, C. M., \& Sordillo, L. M. (2015). Quantification of bovine oxylipids during intramammary Streptococcus uberis infection. Prostaglandins and Other Lipid Mediators , 121 (Pt B), 207-217. https://doi.org/10.1016/j.prostaglandins.2015.09.006

Sato, T., Usui, M., Konishi, N., Kai, A., Matsui, H., Hanaki, H., \& Tamura, Y. (2017). Closely related methicillin-resistant Staphylococcus aureus isolates from retail meat, cows with mastitis, and humans in Japan. PLoS ONE , 12 (10), 1-11. https://doi.org/10.1371/journal.pone.0187319

Schamberger, G. P., Phillips, R. L., Jacobs, J. L., \& Diez-Gonzalez, F. (2004). Reduction of Escherichia coli O157:H7 populations in cattle by addition of colicin E7-producing E. coli to feed. Applied and Environmental Microbiology , 70 (10), 6053-6060. https://doi.org/10.1128/AEM.70.10.6053-6060.2004

Schmidt, T., Kock, M. M., \& Ehlers, M. M. (2017). Molecular characterization of staphylococcus aureus isolated from bovine mastitis and close human contacts in South African dairy herds: Genetic diversity and inter-species host transmission. Frontiers in Microbiology ,8 (APR), 511. https://doi.org/10.3389/fmicb.2017.00511

Sela, U., Euler, C. W., Correa da Rosa, J., \& Fischetti, V. A. (2018). Strains of bacterial species induce a greatly varied acute adaptive immune response: The contribution of the accessory genome. PLoS Pathogens , 14 (1), e1006726. https://doi.org/10.1371/journal.ppat.1006726

Sinclair, M., Fryer, C., \& Phillips, C. J. C. (2019). The benefits of improving animalwelfare from the perspective of livestock stakeholders across asia. Animals , 9 (4). https://doi.org/10.3390/ani9040123

Sinha, M. K., Thombare, N. N., \& Mondal, B. (2014). Subclinical mastitis in dairy animals: incidence, economics, and predisposing factors. TheScientificWorldJournal , 2014 , 523984. https://doi.org/10.1155/2014/523984

Skaalsveen, K., Ingram, J., \& Urquhart, J. (2020). The role of farmers' social networks in the implementation of no-till farming practices.Agricultural Systems , 181 , 102824. https://doi.org/10.1016/j.agsy.2020.102824

Sørensen, U. B. S., Klaas, I. C., Boes, J., \& Farre, M. (2019). The distribution of clones of Streptococcus agalactiae (group B streptococci) among herdspersons and dairy cows demonstrates lack of host specificity 
for some lineages. Veterinary Microbiology ,235 , 71-79. https://doi.org/10.1016/j.vetmic.2019.06.008

Srinandan, C. S., Elango, M., Gnanadhas, D. P., \& Chakravortty, D. (2015). Infiltration of matrix-nonproducers weakens the salmonella biofilm and impairs its antimicrobial tolerance and pathogenicity. Frontiers in Microbiology , 6 (DEC), 1468. https://doi.org/10.3389/fmicb.2015.01468

Sun, Y. V., \& Hu, Y. J. (2016). Integrative Analysis of Multi-omics Data for Discovery and Functional Studies of Complex Human Diseases.Advances in Genetics , 93 , 147-190. https://doi.org/10.1016/bs.adgen.2015.11.004

Sundekilde, U. K., Poulsen, N. A., Larsen, L. B., \& Bertram, H. C. (2013). Nuclear magnetic resonance metabonomics reveals strong association between milk metabolites and somatic cell count in bovine milk. Journal of Dairy Science , 96 (1), 290-299. https://doi.org/10.3168/jds.2012-5819

Swanson, K. M., Stelwagen, K., Dobson, J., Henderson, H. V., Davis, S. R., Farr, V. C., \& Singh, K. (2009). Transcriptome profiling of Streptococcus uberis-induced mastitis reveals fundamental differences between immune gene expression in the mammary gland and in a primary cell culture model. Journal of Dairy Science, 92 (1), 117-129. https://doi.org/10.3168/jds.2008-1382

Tassinari, E., Duffy, G., Bawn, M., Burgess, C. M., McCabe, E. M., Lawlor, P. G., ... Kingsley, R. A. (2019). Microevolution of antimicrobial resistance and biofilm formation of Salmonella Typhimurium during persistence on pig farms. Scientific Reports , 9 (1), 8832. https://doi.org/10.1038/s41598-019-45216-w

Tegegne, H. A., Koláčková, I., Florianová, M., Gelbíčová, T., Wattiau, P., Boland, C., \& Karpíšková, R. (2019). Genome Sequences of Livestock-Associated Methicillin-Resistant Staphylococcus aureus spa Type t899 Strains Belonging to Three Different Sequence Types (ST398, ST9, and ST4034) . Microbiology Resource Announcements ,8 (2). https://doi.org/10.1128/mra.01351-18

Tolosa, T., Verbeke, J., Piepers, S., Supré, K., \& De Vliegher, S. (2013). Risk factors associated with subclinical mastitis as detected by California Mastitis Test in smallholder dairy farms in Jimma, Ethiopia using multilevel modelling. Preventive Veterinary Medicine ,112 (1-2), 68-75. https://doi.org/10.1016/j.prevetmed.2013.06.009

Tong, J., Zhang, H., Zhang, Y., Xiong, B., \& Jiang, L. (2019). Microbiome and Metabolome Analyses of Milk From Dairy Cows With Subclinical Streptococcus agalactiae Mastitis-Potential Biomarkers.Frontiers in Microbiology , 10 , 2547. https://doi.org/10.3389/fmicb.2019.02547

Toniolo, C., Balducci, E., Romano, M. R., Proietti, D., Ferlenghi, I., Grandi, G., ... Janulczyk, R. (2015). Streptococcus agalactiae capsule polymer length and attachment is determined by the proteins CpsABCD. Journal of Biological Chemistry , 290 (15), 9521-9532. https://doi.org/10.1074/jbc.M114.631499

VAN Cleef, B. A., Graveland, H., Haenen, A. P., van de Giessen, A. W., Heederik, D., Wagenaar, J. A., \& Kluytmans, J. A. (2011). Persistence of livestock-associated MRSA after short term occupational exposure to pigs and veal calves. J Clin Microbiol , (1098-660X (Electronic)).

van Duijkeren, E., Horn, L. Ten, Wagenaar, J. A., de Bruijn, M., Laarhoven, L., Verstappen, K., ... Duim, B. (2011, June). Suspected horse-to-human transmission of MRSA ST398. Emerging Infectious Diseases, Vol. 17, pp. 1137-1138. https://doi.org/10.3201/eid1706.101330

van Herten, J., Bovenkerk, B., \& Verweij, M. (2019). One Health as a moral dilemma: Towards a socially responsible zoonotic disease control.Zoonoses and Public Health , 66 (1), 26-34. https://doi.org/10.1111/zph.12536

Van Loo, I., Huijsdens, X., Tiemersma, E., De Neeling, A., Van De Sande-Bruinsma, N., Beaujean, D., ... Kluytmans, J. (2007). Emergence of methicillin-resistant Staphylococcus aureus of animal origin in humans. Emerging Infectious Diseases , 13 (12), 1834-1839. https://doi.org/10.3201/eid1312.070384 
Verhees, F., Malak-Rawlikowska, A., Stalgiene, A., Kuipers, A., \& Klopčič, M. (2018). Dairy farmers' business strategies in Central and Eastern Europe based on evidence from Lithuania, Poland and Slovenia.Italian Journal of Animal Science , 17 (3), 755-766. https://doi.org/10.1080/1828051X.2017.1422154

Verma, A., \& Ambatipudi, K. (2016). Challenges and opportunities of bovine milk analysis by mass spectrometry. Clinical Proteomics ,13 (1), 8. https://doi.org/10.1186/s12014-016-9110-4

Wassenberg, M. W. M., Bootsma, M. C. J., Troelstra, A., Kluytmans, J. A. J. W., \& Bonten, M. J. M. (2011). Transmissibility of livestock-associated methicillin-resistant Staphylococcus aureus (ST398) in Dutch hospitals. Clinical Microbiology and Infection ,17 (2), 316-319. https://doi.org/10.1111/j.14690691.2010.03260.x

Witte, W., Strommenger, B., Stanek, C., \& Cuny, C. (2007). Methicillin-resistant Staphylococcus aureus ST398 in humans and animals, central Europe. Emerging Infectious Diseases , 13 (2), 255-258. https://doi.org/10.3201/eid1302.060924

Yang, Y., Hu, J., Chen, F., Ding, D., \& Zhou, C. (2018). Development of a SCAR Marker-Based Diagnostic Method for the Detection of the Citrus Target Spot Pathogen Pseudofabraea citricarpa. BioMed Research International , 2018 , 7128903. https://doi.org/10.1155/2018/7128903

Zadoks, R. N., \& Fitzpatrick, J. L. (2009, April 1). Changing trends in mastitis. Irish Veterinary Journal , Vol. 62, pp. 59-70. https://doi.org/10.1186/2046-0481-62-S4-S59

Zhang, H., Jiang, H., Fan, Y., Chen, Z., Li, M., Mao, Y., .. Y Yang, Z. (2018). Transcriptomics and iTRAQProteomics Analyses of Bovine Mammary Tissue with Streptococcus agalactiae-Induced Mastitis. Journal of Agricultural and Food Chemistry , 66 (42), 11188-11196. https://doi.org/10.1021/acs.jafc.8b02386

Figure and Table Legends

Fig.1. A major global threat by the spillover of zoonosis and antimicrobial resistance. The figure represents the key characteristics of zoonotic potential of bovine mastitis that depends on the host plasticity, human-to-human transmissibility and broad ecological spread. Pathogenic bacteria causing mastitis evolve abilities to survive in the host when exposed to antibiotics. One of many such strength is biofilm formation, an opportunistic mechanism to defy the host immunity as well as to antibiotics. Subsequently, these resistant pathogens and the residual antibiotics spread by secondary transmission into other animals, humans, and ecosystems creating a myriad of antimicrobial resistance genes that could undergo horizontal gene transfer into different novel opportunistic pathogens. The resistant pathogens, secreted toxins and the residual antibiotics further find different routes (as shown by the red arrows) through manure to plants, contaminated fish in water, meat and milk from infected animals into the food chain.

Fig. 2. The obstacles and opportunities of applying One Health approach in dairy research . This figure depicts to what extent the One-Health approach is applicable to maintain the complex interconnection between animal, human and environmental welfare. The concept has numerous positive aspects and will have a significant impact to control the entry and transmission of pathogens across different hierarchies.

Fig. 3. Integrating multi-omics technologies in One Health Approach. A multi-omics workflow showing different datasets generated using various methodologies from single omics field and post-statistical analysis. The results show different applications of the integrated omics technologies for the One Health Approach. Limitations are listed that have to be addressed for successful implementation.

Supplementary Table S1. One-Health key points applicable across different hierarchies to control bovine mastitis in dairy industry.

Table 1. Records of the transmission of mastitis causing pathogenic strains to humans due to close proximity, or food products. 


\begin{tabular}{lll}
\hline Study & Pathogen, Strain & Place \\
\hline Study & & \\
\hline (G. K. Paterson et al., 2012) & Pathogen, Strain & Place \\
(Hata et al., 2010) & LA-MRSA & United Kingdom \\
(G. K. Paterson et al., 2014) & LA-MRSA & Japan \\
(Juhász-Kaszanyitzky et al., 2007) & mecC MRSA & Great Britain \\
(García-Álvarez et al., 2011b) & MRSA & Hungary \\
(Bardiau et al., 2013) & MRSA & United Kingdom and Denmark \\
(Lee, 2003) & MRSA ST398 & Belgium \\
(Dhup, Kearns, Pichon, \& Foster, 2015) & MRSA & Korea \\
(Wassenberg, Bootsma, Troelstra, Kluytmans, \& Bonten, 2011) & MRSA ST398 & England \\
(Sato et al., 2017) & MRSA Netherlands \\
(Lyhs et al., 2016d) & Group B Streptococcus & Finan \\
(Sørensen, Klaas, Boes, \& Farre, 2019) & Group B Streptococcus & Denmark \\
(Cobo-Angel et al., 2019b) & Group B Streptococcus & Colombia \\
(Martinez et al., 2000) & Group B Streptococcus & Canada \\
(Manning et al., 2010) & Group B Streptococcus & Michigan \\
(Dogan, Schukken, Santisteban, \& Boor, 2005) & Group B Streptococcus & New York State \\
(Van Loo et al., 2007) & NT-MRSA & The Netherlands \\
(Schmidt, Kock, \& Ehlers, 2017) & S.aureus & South Africa \\
\hline
\end{tabular}

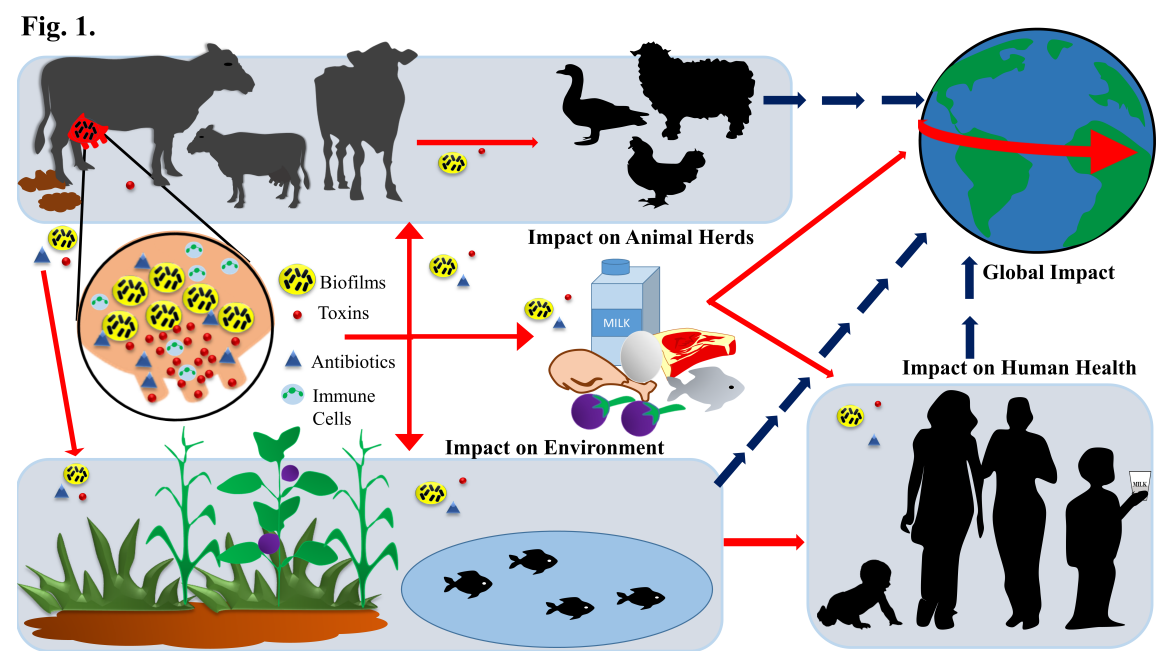


Fig. 2.

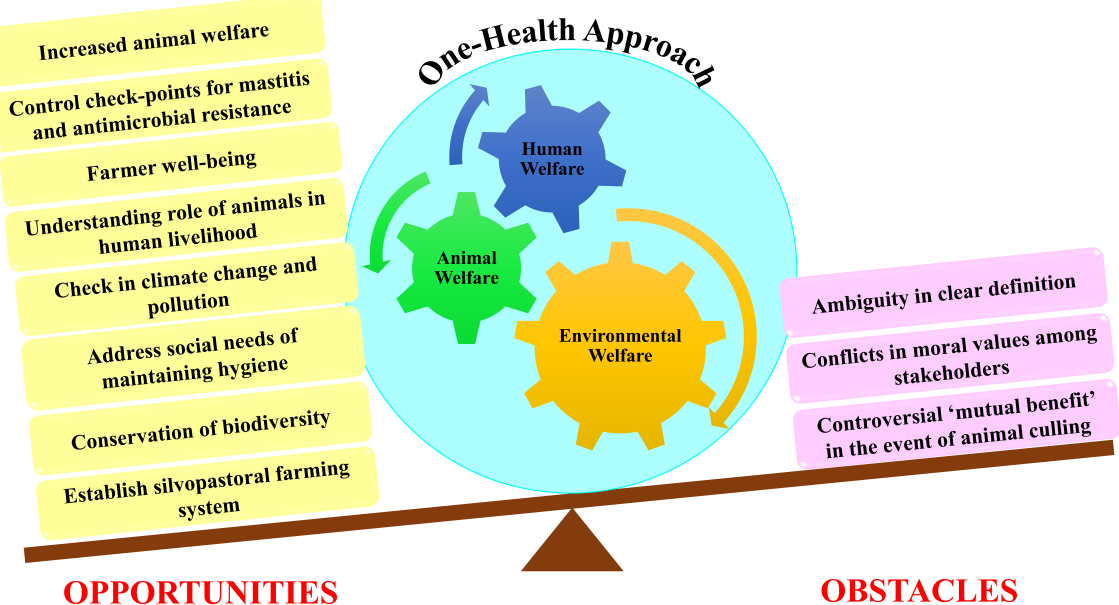

Fig. 3.

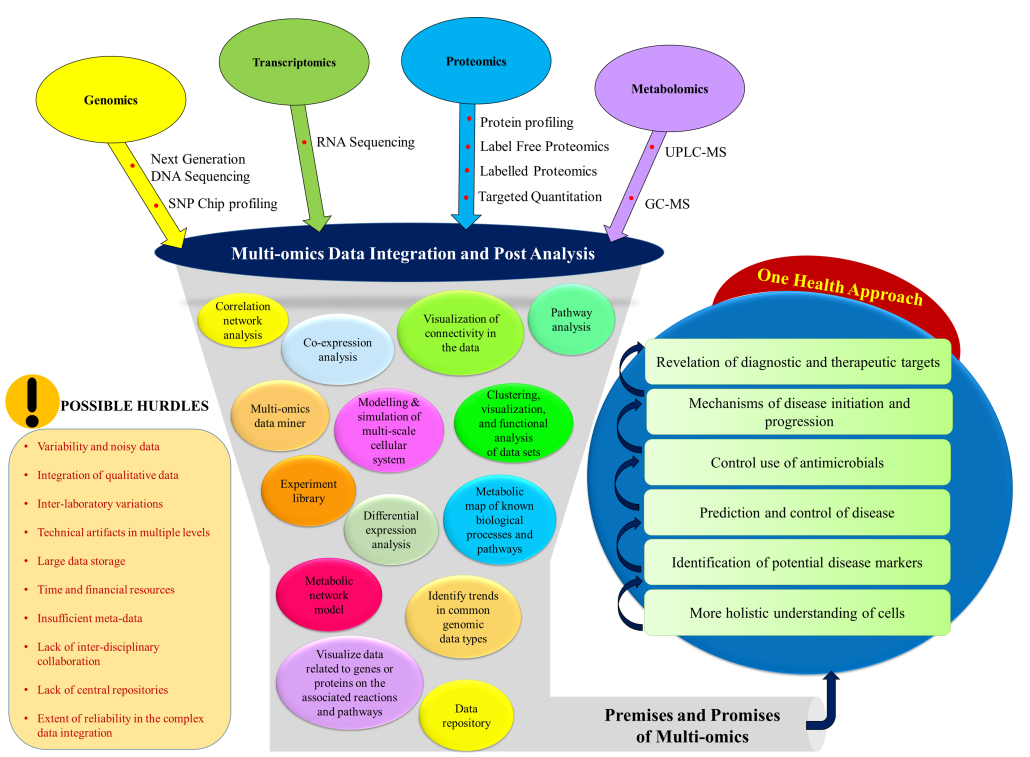

